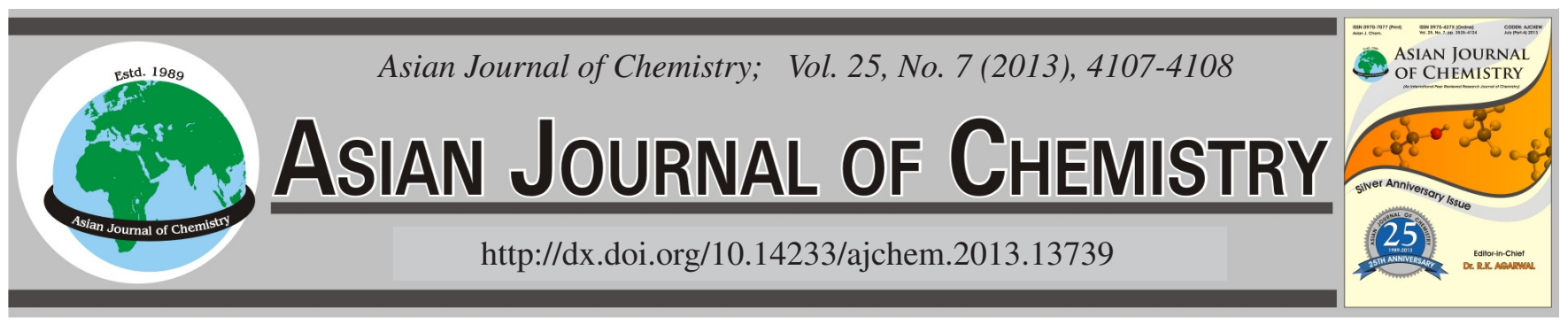

NOTE

\title{
Estimation of $\mathrm{H}_{2} \mathrm{O}_{2}$ Content in Free Radical Bromination and Oxidation Reactions by the $\mathrm{H}_{2} \mathrm{O}_{2}$-HBr System Generated Effluent Samples by Iodometry Method
}

\author{
K. Tirumala RaO ${ }^{1, *}$, Y.V. Mohan ${ }^{1}$, Naveen $^{2}$ and L. Vaikunta RaO ${ }^{2}$
}

${ }^{1}$ Analytical Research, Ecologic Technologies (P) Ltd., Hyderabad-500 049, India

${ }^{2}$ GITAM College of Science and Technology, Visakhapatnam-530 045, India

*Corresponding author: E-mail: tirumalwithu@gmail.com

\begin{abstract}
A simple accurate and precise green analytical iodometric titration method was optimized for the estimation of hydrogen peroxide $\left(\mathrm{H}_{2} \mathrm{O}_{2}\right)$ content in free radical bromination and oxidation reactions by using hydrogen peroxide $\left(\mathrm{H}_{2} \mathrm{O}_{2}\right)$ and hydrogen bromide $(\mathrm{HBr})$ system generated effluent samples. These process generated effluents are containing good amount of $\mathrm{H}_{2} \mathrm{O}_{2}$ and $\mathrm{HBr}$ reagents. Hydrogen peroxide will react rapidly with other compounds found air and if released to soil, will be broken down by reacting with other compounds. Hence the estimation of $\mathrm{H}_{2} \mathrm{O}_{2}$ is very crucial and important towards the protection of the environment. In view of this we have applied iodometry for this system. During straightforward analysis with $\mathrm{KMnO}_{4}$ titration method was not helpful to estimate the $\mathrm{H}_{2} \mathrm{O}_{2}$ content in this system and USP general chapters thiosulphate standardization by iodometry method was also attempted, which is not helping to estimate the $\mathrm{H}_{2} \mathrm{O}_{2}$ in the system again. The same iodometry titration method was attempted in presence of sulphuric acid medium which is encouraging accurate estimation of $\mathrm{H}_{2} \mathrm{O}_{2}$ content in bromination and oxidation reactions by using $\mathrm{H}_{2} \mathrm{O}_{2}$ and $\mathrm{HBr}$ process generated effluents.
\end{abstract}

Key Words: Iodometry titration, Bromination, Oxidation, E-factor, Green chemistry, Green analytical method.

Hydrogen peroxide reacts rapidly with other compounds found air and if released to soil, will be broken down by reacting with other compounds. Hence the estimation of $\mathrm{H}_{2} \mathrm{O}_{2}$ is very crucial and important towards the protection of the environment ${ }^{1}$. Hydrogen peroxide is a quite reactive substance in the presence of other substances, elements, radiation, materials or cells. Both biotic and a biotic degradation processes are important routes in the removal of hydrogen peroxide in the environment. Hydrogen peroxide decomposes into water and oxygen at rates which depend on contact with catalytic materials. This reaction is highly exothermic and takes place in the presence of small amounts of catalyst even in aqueous solution ${ }^{2}$. In view of this hydrogen peroxide content is very important in process generated effluent samples. This paper deals with the determination of $\mathrm{H}_{2} \mathrm{O}_{2}$ in free radical bromination and oxidation by using $\mathrm{H}_{2} \mathrm{O}_{2}-\mathrm{HBr}$ system ${ }^{3}$ given effluent samples. In order to estimate the $\mathrm{H}_{2} \mathrm{O}_{2}$ in our samples attempted by $\mathrm{KMnO}_{4}$ titration method ${ }^{4}$, this is not helping to identifying the end point due to evolving the bromine gas during titration and also attempted iodometry basic condition sodium bicarbonate media ${ }^{5}$ which is also not helping to the estimation of $\mathrm{H}_{2} \mathrm{O}_{2}$. The same iodometry titration method was attempted in presence of sulphuric acid medium which is encouraging accurate estimation of $\mathrm{H}_{2} \mathrm{O}_{2}$ content in bromination and oxidation reactions process generated effluents. By this method $\mathrm{H}_{2} \mathrm{O}_{2}$ contents in the range of 2-8\% levels in our samples and also established detection level $0.001 \%$ (10 ppm). Spiking experiments also performed in the range from 0.001 to $10 \%$ level in sample matrix. This help us to optimize the reaction by addition of sufficient amount of $\mathrm{H}_{2} \mathrm{O}_{2}$ in the reaction medium and also helps to reduce $\mathrm{H}_{2} \mathrm{O}_{2}$ concentration in effluents. Indirectly to decrease the e-factor values in the above chemical reactions to encourage the green chemistry concepts ${ }^{6}$. The method was validated in limited parameters and it is showing satisfactory results ${ }^{7}$. The optimized method was simple precise and accurate green analytical method ${ }^{8}$ for the estimation of $\mathrm{H}_{2} \mathrm{O}_{2}$ in our effluent samples.

Halogenations and oxidations reactions by using $\mathrm{H}_{2} \mathrm{O}_{2}$ and $\mathrm{HBr}$ reagents in the process generated effluent sample taken from process research department of custom pharmaceutical services of Dr. Reddy's Laboratories Limited, Hyderabad, India. Analytical reagent grade Sodium thiosulphate pentahydrate, potassium iodide, hydrogen peroxide $50 \% \mathrm{v} / \mathrm{v}$ and sulphuric acid $98 \% \mathrm{v} / \mathrm{v}$ were purchased from Merck, Germany. High pure water was prepared by using Millipore Milli Q plus purification system. 
Preparation and standardization of $0.1 \mathrm{~N}$ sodium thiosulphate pentahydrate solution: Preparation standardization of $0.1 \mathrm{~N}$ sodium thiosulphate solution followed as per USP general chapters.

Preparation of sample solution: Weighed $1 \mathrm{~g}$ of test sample and transferred into $100 \mathrm{~mL}$ volumetric flask and made up to mark with water.

Preparation of standard solutions: A stock solution prepared $20 \% \mathrm{v} / \mathrm{v}$ and further diluted $0.001,0.010 .1,1,5$ and $10 \% \mathrm{v} / \mathrm{v}$ solutions for linearity and method sensitivity.

Preparation of spiked solutions: Spiked sample solutions were prepared $10 \% \mathrm{v} / \mathrm{v}, 5 \% \mathrm{v} / \mathrm{v}, 1 \% \mathrm{v} / \mathrm{v}, 0.1 \% \mathrm{v} / \mathrm{v}$ of $\mathrm{H}_{2} \mathrm{O}_{2}$ added in the samples.

Dilute the sample solution in the level of $0.3 \% \mathrm{v} / \mathrm{v}$ approximately into $250 \mathrm{~mL}$ into iodine flask added $90 \mathrm{~mL}$ water, mixed thoroughly and added $0.75 \mathrm{~g}$ of potassium iodide, 3-5 mL of concentrated sulphuric acid. Kept in dark place for 10-15 min to liberate the free iodine. Then the solution becomes yellowish it indicates the free iodine was produced by the reaction with $\mathrm{H}_{2} \mathrm{O}_{2}$. After this solution titrated against $0.1 \mathrm{~N}$ standardized thiosulphate solution by addition of starch solution. The observed endpoint is blue to colour discharge of the sample solution.

Precision: A standard solution of $5 \% \mathrm{v} / \mathrm{v}_{2} \mathrm{H}_{2}$ is used for this study and five times performed titration in the same level. The \% RSD calculated for the $\mathrm{H}_{2} \mathrm{O}_{2}$ content.

Linearity: The above standard linearity solutions were used for this study and estimates $\mathrm{H}_{2} \mathrm{O}_{2}$ in each level of solution and plotted the graph concentrations on $\mathrm{x}$-axis and peroxide content on y-axis.

Accuracy and limit of detection: The above spikes solutions are estimated peroxide content and calculated $\%$ Recovery against standard solution and also checked detection limit by this method.

The $\%$ RSD of peroxide content ( $\% \mathrm{w} / \mathrm{w})$ was found to be less than $2 \%$ and the corresponding results are given in Table-1. Correlation co-efficient value was observed in the linearity parameter 0.9982 and the respective results are shown in Table-2, linearity graph also shown in Fig. 1. \% Recovery values are in the range of 79.1 to $90.9 \%$ and the obtained recovery values are presented in Table- 3 . This method is able to detect $0.001 \% \mathrm{v} / \mathrm{v}$ level of peroxide in the above samples. Based on the results, the method is linear, precise and accurate for the estimation of peroxide content in the described effluent samples.

\begin{tabular}{ccc}
\multicolumn{3}{c}{ TABLE-1 } \\
PRECISION TEST RESULTS \\
\hline S. No. & Trial & $\mathrm{H}_{2} \mathrm{O}_{2}$ content \\
\hline 1. & Trail -1 & 4.95 \\
2. & Trail -2 & 4.91 \\
3. & Trail -3 & 4.98 \\
4. & Trail -4 & 4.85 \\
5. & Trail -5 & 4.75 \\
6. & Trail -6 & 4.94 \\
\hline & Mean & 4.90 \\
& \%RSD & 1.72 \\
\hline
\end{tabular}

\begin{tabular}{ccc}
\multicolumn{3}{c}{ TABLE-2 } \\
LINEARITY TEST RESULTS \\
\hline S. No. & $\begin{array}{c}\text { Conc. of } \mathrm{H}_{2} \mathrm{O}_{2} \text { Sol'n } \\
\text { used } \% \text { v/v) }\end{array}$ & $\begin{array}{c}\text { Obtained conc. of } \\
\mathrm{H}_{2} \mathrm{O}_{2}(\% \text { v/v) }\end{array}$ \\
\hline 1. & 0.00985 & 0.00801 \\
2. & 0.0985 & 0.0885 \\
3. & 0.985 & 0.899 \\
4. & 4.925 & 4.341 \\
5. & 9.85 & 9.855 \\
\hline Correlation Co & Slope & Intercept \\
efficient (r) & & \\
\hline 0.9982 & 0.989 & -0.101 \\
\hline
\end{tabular}

\section{Conclusion}

The current iodometry method is good for quantitative determination of peroxide content in effluent samples which are generated from Bromination and oxidation reactions by using $\mathrm{H}_{2} \mathrm{O}_{2}$ and $\mathrm{HBr}$. The method was partially validated showing satisfactory data for the limited method validation parameters tested.

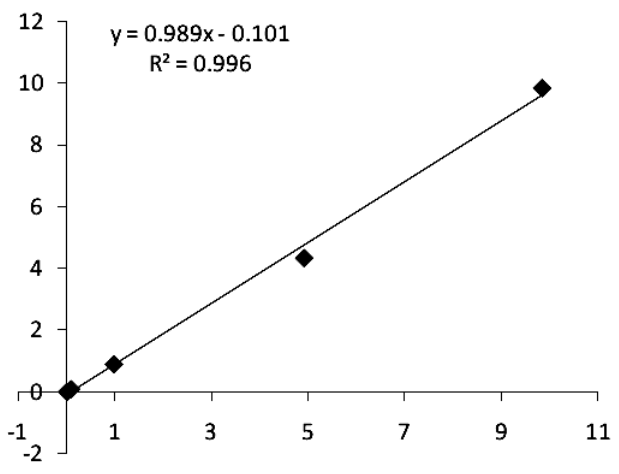

Fig. 1. Linearity graph

\begin{tabular}{cccc}
\multicolumn{4}{c}{ TABLE-3 } \\
\multicolumn{4}{c}{ ACCURACY TEST RESULTS } \\
\hline S. No. & $\begin{array}{c}\text { Amount of } \mathrm{H}_{2} \mathrm{O}_{2} \text { added } \\
(\% \mathrm{v} / \mathrm{v})\end{array}$ & $\begin{array}{c}\text { Obtained } \\
(\% \mathrm{v} / \mathrm{v})\end{array}$ & $\begin{array}{c}\% \text { of } \\
\text { recovery }\end{array}$ \\
\hline 1. & 0.00985 & 0.00785 & 79.7 \\
2. & 0.0985 & 0.0801 & 81.3 \\
3. & 0.985 & 0.811 & 82.3 \\
4. & 4.925 & 4.183 & 84.9 \\
5. & 9.85 & 8.952 & 90.9 \\
\hline
\end{tabular}

\section{REFERENCES}

1. Agency for Toxic Substance and Disease Registry for Hydrogen Peroxide, vol. 1 (2002),

2. European Risk Assessment Report on Hydrogen Peroxide, pp. 26-35 (2003),

3. A. Podgoršek, S. Stavber, M. Zupan and J. Iskra, Tetrahedron Lett., 47, 7245 (2006).

4. J. Mendham, R.C. Denny, J.D. Barnes and M.J.K. Thomas, Vogel Text Book of Quantitative Chemical Analysis, edn. 6, p. 366 (2009).

5. General Chapters Reagents and Volumetric Solutions United States Pharmacopeia Titrimetry USP 34 NF $29-1$ and <541> (2011).

6. P. Anastas and N. Eghbali, Chem. Soc. Rev. Royal Soc. Chem., 39, 301 (2010),

7. Validation of Analytical Procedures: Text and Methodology ICH Q2 (R1) Step 4 (2005),

8. M. Tobiszewski, A. Mechlinska and J. Namiesnik, Chem. Soc. Rev., 39, 2869 (2010). 